\title{
KESIAPSIAGAAN DESA TERHADAP BENCANA TANAH LONGSOR
}

\author{
Linda Octavia ${ }^{1}$, Eko Prawoto ${ }^{2}$ \\ 1,2. Program Studi Arsitektur, Fakultas Arsitektur dan Desain, Universitas Kristen Duta Wacana, \\ Jl. dr. Wahidin Sudirohusodo No. 5-25, Yogyakarta \\ Email: lindaoctavia2010@gmail.com¹, ekoprawoto@yahoo.com²
}

\begin{abstract}
Abstrak
Bencana yang pernah terjadi hampir dapat dipastikan akan terjadi lagi dan kita tidak tahu kapan dan dimana bencana akan terjadi lagi. Persiapan sedapat-dapatnya dan pemahaman tentang apa yang harus dilakukan ketika bencana terjadi merupakan sebuah langkah penting yang harus dilakukan. Selain itu, pengetahuan atau pengalaman tentang bencana juga harus diteruskan kepada generasi berikutnya. Kajian ini memakai metode wawancara dan pengamatan langsung untuk bisa mendapatkan data tentang tanda-tanda kebencanaan yang terjadi di desa Kebonharjo. Wawancara dilakukan dengan para warga desa, sedangkan pengamatan dilakukan di beberapa lokasi di mana terjadi bencana tanah longsor. Hasil yang diperoleh kemudian dianalisis untuk bisa mendapatkan tanda-tanda yang paling signifikan yang bisa dijadikan patokan bagi warga ketika menjelang terjadinya bencana. Dengan adanya dokumentasi dan pengetahuan yang tertulis tentang tandatanda itu, maka pengetahuan tersebut akan lebih banyak diketahui oleh masyarakat dan bisa menjadi bekal yang bermanfaat ketika mereka menemui lokasi yang dirasa mengandung tandatanda bencana dan bisa mengidentifikasikannya dengan cepat. Perubahan dari pengetahuan lisan menjadi pengetahuan tertulis menjadi pilihan yang tepat sehingga kesiapsiagaan desa menghadapi bencana menjadi lebih tinggi.
\end{abstract}

Kata kunci: kesiapsiagaan, pengetahuan tertulis, tanah longsor, tanda-tanda.

\begin{abstract}
Title: Village Preparedness Against Landslide Disaster

Disasters that have previously occurred can almost be guaranteed that they would most likely reoccur without our knowing when and where they would take place once again. Maximum preparation and understanding about what we should do during events of disaster are substantial measures that we must take. In addition, knowledge or experiences relating to disasters should also be passed down to the next generation. This study employed methods of in-depth interviews and direct observations to acquire data regarding indicators of disasters found in the village of Kebonharjo. The interviews were performed with the villagers, while observations were carried out in a number of locations where landslides had occurred. The acquired results were subsequently analyzed in order to gain an understanding of the most significant indicators that can be used as a standard for the villagers to be prepared in the event of a disaster. The availability of written knowledge and documentation pertaining to these indicators will consequently lead to such knowledge being more widely known by the community and they can also serve as a useful resource for the villagers when they find locations that are considered to show indications of disaster, in which they can then make a quick identification of the situation. Transforming oral knowledge into a written one is admittedly an appropriate choice in order to strengthen the village's preparedness against disaster.
\end{abstract}

Keywords: preparedness, written knowledge, landslide, indications. 


\section{Pendahuluan}

Bencana alam yang pernah terjadi di suatu tempat, hampir dapat dipastikan akan terjadi lagi suatu saat. Hanya masalahnya kita tidak tahu kapan dan dimana bencana itu akan terjadi lagi. Sehingga melakukan persiapan sedapat-dapatnya dan semampunya untuk memahami apa yang harus dilakukan ketika bencana itu terjadi, serta memberikan pesan sebagai bekal bagi generasi berikutnya tentang pengetahuan serta kesiapan bencana, agaknya merupakan langkah penting yang harus dilakukan. Hal ini dilakukan supaya pengetahuan tentang tanda-tanda bencana bukan menjadi pengetahuan yang 'hilang', tetapi menjadi pengetahuan empiris yang diturunkan dari generasi ke generasi.

Kesiapsiagaan tersebut antara lain diwujudkan dengan mengenali secara lebih dini apa tanda-tanda yang ada sebelum terjadinya longsor. Juga apa yang menjadi pengalaman empirik masyarakat dalam mengenali tandatanda tersebut. Dengan demikian, masyarakat menjadi subjek yang aktif dalam proses penyusunan pengetahuan tentang bencana alam yang ada di tempat mereka berada.

Desa Kebonharjo sering terjadi bencana, sehingga perlu ada kesadaran yang menjadi bagian dari nilai dan sikap hidup. Dahulu nilai dan sikap hidup sadar akan bencana alam pernah dimiliki oleh warga Desa Kebonharjo, namun sejalan dengan perubahan jaman, kearifan lokal itu 'terlupakan'.

Saat ini, inisiatif dari luar untuk membagikan informasi dan pengetahuan tentang DRR (Disaster Risk Reduction) diperlukan. Namun, membangun kesadaran dari dalam dan dikaitkan dengan pengetahuan lokal akan membuat kesiapsiagaan ini lebih berkelanjutan dan kokoh.
Dalam tulisannya, Mekar (2014) menyatakan bahwa faktor terjadinya longsor pada suatu lereng bisa dikelompokkan menjadi faktor internal dan faktor eksternal. Faktor internal terdiri dari kondisi geologi batuan dan tanah penyusun lereng, kemiringan lereng, hidrologi dan struktur geologi. Sedangkan faktor eksternal atau disebut juga sebagai faktor pemicu adalah curah hujan, vegetasi penutup dan penggunaan lahan pada lereng.

Dari pendapat di atas, kajian ini memiliki dasar yang cukup untuk menjadi pedoman ketika melakukan wawancara dengan masyarakat ataupun ketika peninjauan langsung ke lapangan. Dengan demikian, ketika melakukan diskusi dengan masyarakat, sudah ada prejudice yang berupa pemahaman tentang faktor internal dan eksternal yang bisa memicu terjadinya longsor.

Tanah longsor bukanlah bencana yang berdiri sendiri, tidak terkait dengan apapun, melainkan berhubungan erat dengan beberapa hal, diantaranya yaitu pengetahuan, masyarakat, aktivitas dan lain sebagainya. Berdasarkan presentasi Murai san dari NGO Collaboration Center - Japan di Balai Desa Kebonharjo, 19 November 2017, dia mengatakan bahwa ada lima hal pokok atau prinsip yang harus dilakukan oleh warga ketika menghadapi bencana, yaitu:

1. Menginformasikan adanya/ terjadinya bencana secara cepat.

2. Mengetahui terjadinya tanda-tanda akan adanya bencana.

3. Bertindak dengan tepat dan cepat.

4. Mempelajari pengetahuan tentang kebencanaan secara terus-menerus.

5. Meningkatkan kesiapsiagaan
terhadap bencana.

Kelima hal ini dilakukan dengan tujuan agar dapat menurunkan dampak bencana yang sangat merugikan 
kehidupan manusia. Kegiatan-kegiatan yang didasarkan oleh kelima hal tersebut juga bukan merupakan kegiatan yang terpisah antara yang satu dengan lainnya, melainkan merupakan sebuah siklus yang saling berhubungan dan terkait.

Pada poin kedua dinyatakan bahwa warga harus mengetahui (secara lebih dini) tanda-tanda terjadinya suatu bencana, sehingga warga bisa melakukan penyelamatan dan evakuasi secara tepat untuk menghindari jatuhnya korban jiwa maupun materi. Poin kedua inilah yang menjadi titik penting dalam kajian ini, di mana tanda-tanda terjadinya bencana diidentifikasi secara lebih nyata agar menjadi pedoman yang berguna bagi masyarakat.

\section{Metode Penelitian}

Penelitian yang telah dilakukan ini merupakan hasil dari berinteraksi secara intensif dengan warga Desa Kebonharjo dalam kurun waktu satu tahun. Penelitian ini memiliki sifat kualitatif dan deskriptif dengan menggunakan lima hal pokok atau prinsip tentang kebencanaan sebagai pijakan dalam melakukan pencatatan.

\footnotetext{
Menurut Moleong (2007) pengumpulan data dalam penelitian kualitatif dapat dilakukan melalui pengumpulan dokumen, pengamatan dan wawancara. Dalam penelitian ini peneliti mengumpulkan data Desa Kebonharjo melalui wawancara dengan para warga masyarakat Desa Kebonharjo tentang apa dan bagaimana mereka membaca tandatanda bencana longsor yang mungkin akan terjadi, serta hal-hal apa yang mereka bisa refleksikan kembali terkait tanda dan sinyal-sinyal bencana yang telah mereka alami ketika menjelang terjadinya bencana.
}

Data atau informasi yang lebih teknis didapat dari fasilitator NGO Collaboration Center - Japan, BNPB (Badan Nasional Penanggulangan Bencana) dan studi banding yang dilakukan oleh penulis ke Jepang. Sedangkan data yang lebih sosial atau lokal didapat dari wawancara dengan tokoh-tokoh desa yang sudah senior dan memiliki pengalaman tentang kebencanaan.

Data yang didapatkan tersebut kemudian diproses melalui analisis data dan interpretasi data. Moleong (2007) juga mengatakan bahwa analisis data adalah proses untuk mengorganisasikan dan mengurutkan data kedalam pola, kategori dan satuan uraian dasar sehingga dapat ditemukan tema dan dapat dirumuskan hipotesis kerja seperti yang disarankan oleh data.

Dari berbagai macam tanda-tanda yang sudah didapatkan, kemudian dicari pola-pola yang sama untuk didapatkan tanda-tanda yang signifikan dan teruji untuk dijadikan sebagai sebuah materi pengetahuan tentang tanda-tanda bencana.

\section{Hasil dan Pembahasan}

\section{Jejak Rekam Bencana Tanah Longsor}

Melihat topografi dan juga konfigurasi geologis daerah pedesaan di Kebonharjo, terlihat adanya beberapa titik yang rawan, yang bahkan sering terjadi bencana tanah longsor. Cerita dari desa lain di sekitarnya adalah adanya kejadian desa yang 'tenggelam' atau tertimbun tanah yang bergerak dari dataran di atasnya menunjukkan adanya kerawanan laten (tersembunyi) atas itu.

Dalam situasi yang demikian dan sudah berlangsung sejak waktu yang sangat lama, telah disikapi dan 
kemudian dihidupi menjadi Pengetahuan modern atas bencana serangkaian pengetahuan lokal yang kemudian muncul karena pengalaman kemudian 'mengkristal' menjadi patokan atau ritual yang dilakukan sebagai bagian dari ritual budaya setempat. Sikap dan nilai dari budaya setempat yang pada dasarnya ingin menggapai keadaan yang 'aman' atau menurut istilah lain sebagai slamet. Slamet dapat dipahami sebagai terjaganya kehidupan ditengah kejadian alam semesta yang kadang bisa sangat dahsyat itu. empiris kejadian alam yang dahsyat dari berbagai tempat, kemudian disusun dan dibagikan kepada sesamanya. Gabungan antara pengetahuan yang modern dan tradisi diperlukan di sini, yakni mencatat kembali pengetahuan lokal yang sebelumnya tidak dituliskan agar bisa menjadi sumber pengetahuan yang lebih mudah diakses oleh semua orang.

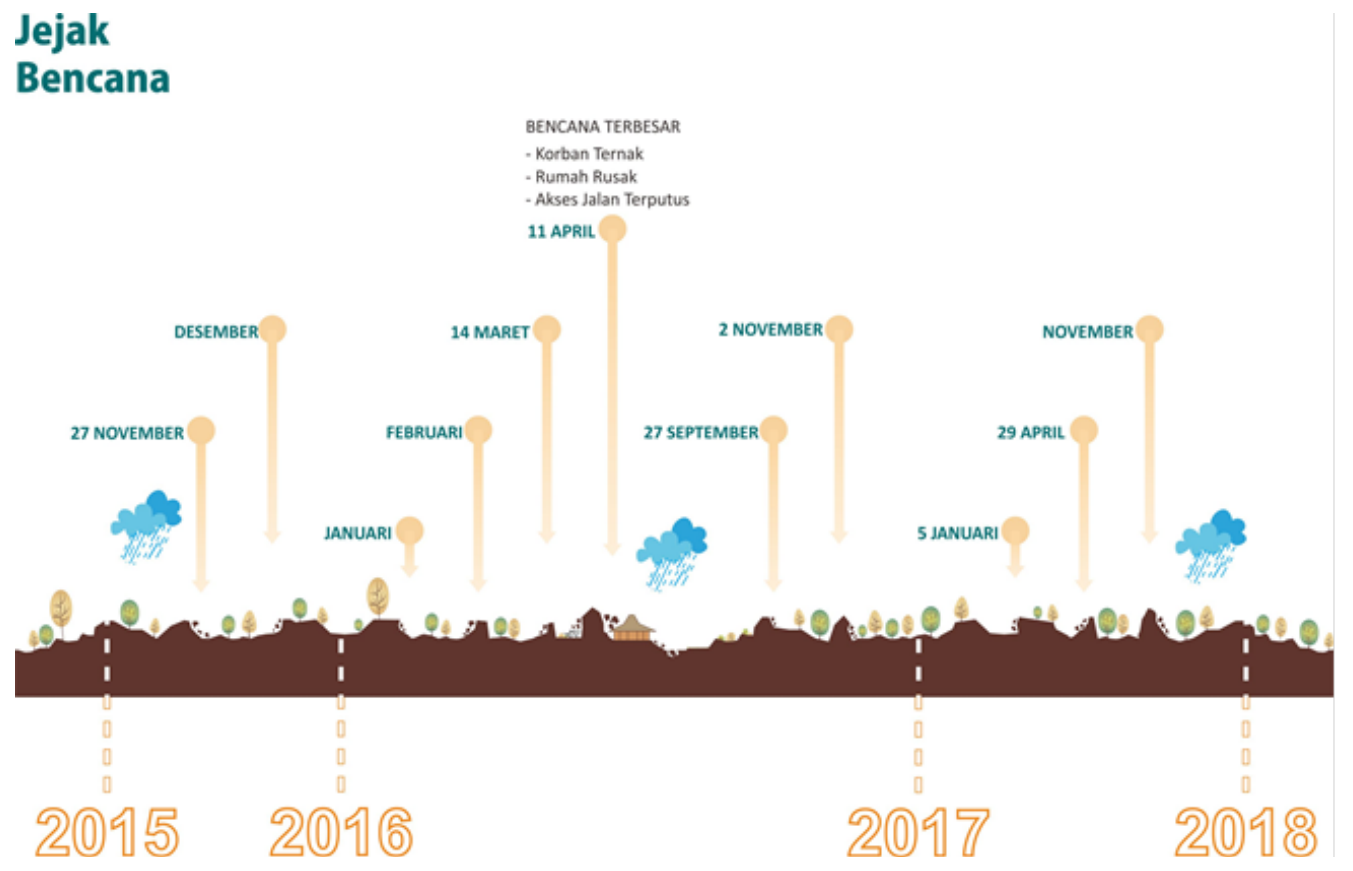

Gambar 1. Grafis jejak bencana di Desa Kebonharjo sejak tahun 2015-2018 Sumber: Hasil wawancara, 2018

Kemampuan survival manusia antara lain juga disebabkan oleh kemampuannya untuk melakukan proses 'pembelajaran' atas apa yang dialami, baik langsung maupun tidak. Kejadian alam yang dahsyat kemudian mendorong manusia untuk lebih seksama melakukan adaptasi dan antisipasi, namun juga melakukan upaya-upaya praktis dan teknis untuk menyikapi dan mengatasi dampak buruk dari kejadian alam yang dahsyat itu.
Berbincang dengan tim Forum Pengurangan Risiko Bencana (FPRB) Desa Kebonharjo saat melakukan review peta bencana menghasilkan informasi tentang catatan bencana tanah longsor di Desa Kebonharjo. Jejak rekam bencana tanah longsor yang tercatat dan terdokumentasi adalah sejak tahun 2015. Ini menunjukkan bahwa sudah mulai ada kesadaran untuk mencatat peristiwa bencana yang terjadi sehingga dapat dijadikan pengetahuan untuk lebih siap 
dalam menghadapi bencana di masamasa yang akan datang.

\section{Bencana yang Mungkin Terjadi}

Sesuai dengan karakteristik alam yang ada di Desa Kebonharjo, maka bencana yang mungkin terjadi di daerah ini adalah: kekeringan (ketika musim kemarau terlalu panjang) dan tanah longsor (ketika curah hujan yang terjadi relatif tinggi). Kejadian bencana ini merupakan pola alami yang penanganannya dibedakan menjadi dua hal yang berbeda:

1. Kekeringan

Tindakan yang perlu dilakukan adalah pendataan dan identifikasi warga yang terdampak kekeringan, kemudian dilakukan dropping air di wilayah-wilayah yang mengalami kekeringan.

2. Tanah Longsor

Sedangkan untuk tanah longsor, tanda yang perlu diwaspadai adalah rekahan pada tanah ketika curah hujan relatif tinggi, maka warga harus waspada jika tanah terasa bergerak/ longsor.

\section{Bencana Tanah Longsor}

Secara teknis dapat disebutkan bahwa jika ada lapisan tanah yang cukup luas bergerak atau berpindah posisi, meluncur ke bawah dengan membawa apapun di atasnya, hal ini dikenal dengan sebutan tanah longsor. Kejadian alam ini disebabkan karena terjadinya intrusi air melalui retakan di tanah ketika hujan deras dengan curah sangat tinggi sehingga terjadi lapisan jenuh air yang sangat lembek dan tidak mampu mendukung lapisan di atasnya, sehingga lapisan di atasnya meluncur bebas mengikuti gaya gravitasi.

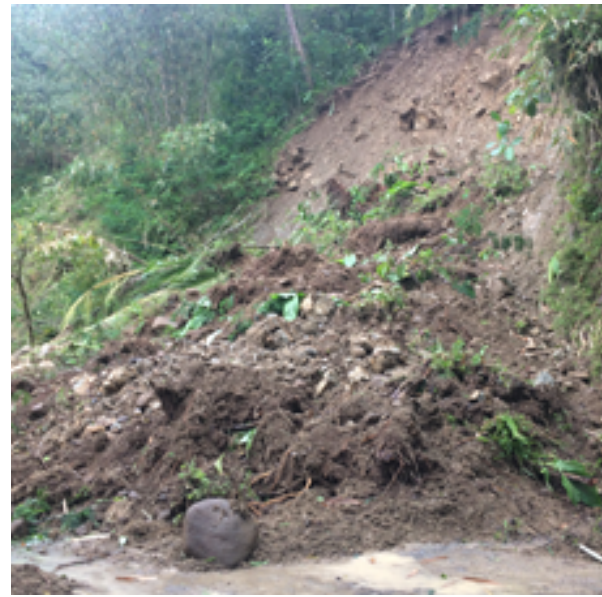

Gambar 2. Kondisi pasca longsor bulan November 2017

Sumber: Dokumentasi Octavia, 2017

\section{Sebelum Terjadinya Tanah Longsor}

Sebetulnya tanah longsor tidak terjadi di sembarang tempat. Hanya pada area yang relatif miring dan curam, juga kondisi lapisan tanah yang kondisi kohesi atau ikatan butirannya agak lemah. Dan ketika lapisan tanah diatasnya retak-retak lebar, yang akan menyalurkan air ketika hujan deras untuk masuk meresap ke lapisan bawah tanah.
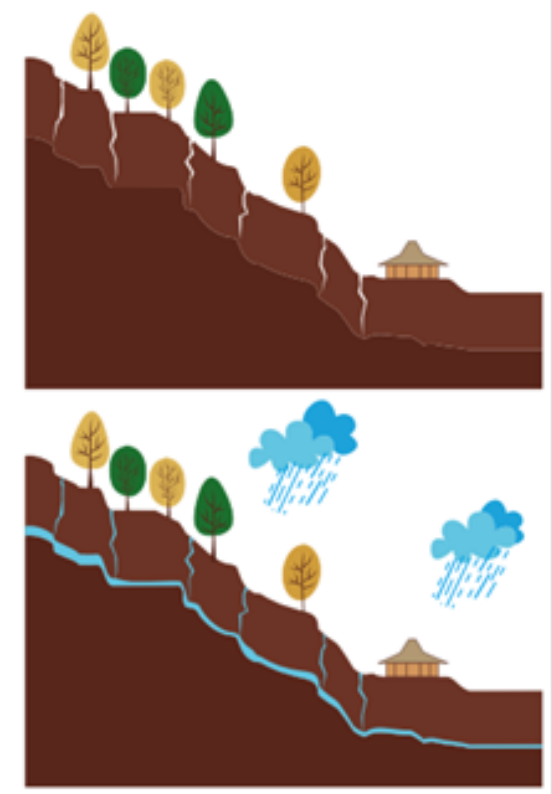

Gambar 3. Ilustrasi sebelum terjadinya tanah longsor

Sumber: Dokumentasi tim penelitian, 2018 

Saat Akan Terjadi Bencana Tanah
Longsor: Tanda-tanda Terjadinya
Bencana Tanah Longsor
Tanda-tanda kemungkinan tanah longsor dapat diketahui dengan melihat karakteristik gejala tadi. Pada saat lapisan tanah itu mulai bergerak meluncur, bisa dilihat tanda-tanda sekunder misalnya terjadi guguran kerikil atau batuan, terjadinya suara berderak karena akar pohon yang tercerabut, atau posisi pohon yang cenderung miring roboh karena pergeseran tumpuan akarnya.

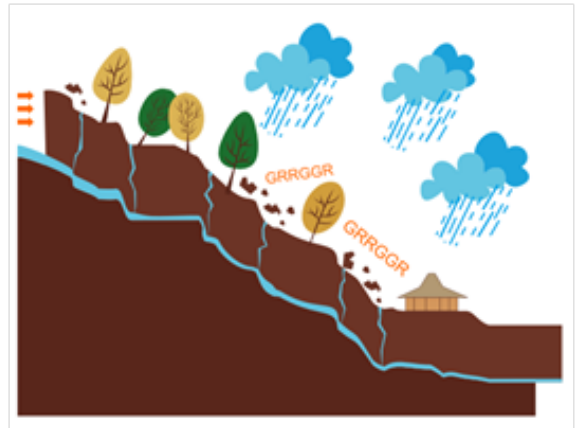

Gambar 4. Ilustrasi saat akan terjadi tanah longsor

Sumber: Dokumentasi tim penelitian, 2018

\section{Ketika Terjadi Bencana Tanah Longsor}

Tanah yang cukup luas areanya akan meluncur turun dengan membawa apapun diatasnya, suara gemuruh dan getaran. Dapat dibayangkan betapa mengerikannya fenomena alam ini, tidak ada kekuatan lain yang mampu menahan pergerakan tanah ini. Maka secepatnyalah manusia harus menghindari atau menjauh dari arah longsoran tanah ini. Beberapa kejadian tanah longsor merupakan pergerakan lapisan yang sangat tebal, ini sangat berbahaya bahkan dapat menimbun area yang luas yang berada dibawahnya.

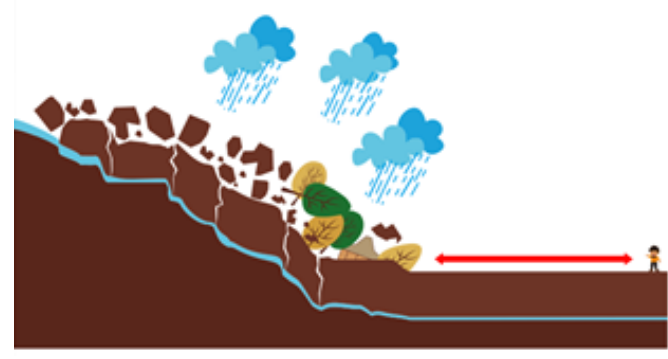

Gambar 5. Ilustrasi ketika terjadi tanah longsor

Sumber: Dokumentasi tim penelitian, 2018

\section{Pasca Bencana Tanah Longsor}

Setelah lapisan tanah yang tebal itu meluncur kebawah, suatu saat akan berhenti ketika menemukan titik kestabilannya. Longsoran yang terjadi bisa diibaratkan seperti lapisan tanah yang terbuka menganga karena sejumlah volume tanah diatasnya telah bergeser. Lumpur, tanah basah serta bebatuan juga pohon-pohon diatasnya menjadi berserakan. Tindakan yang bisa dilakukan adalah mencri korban manusia yang tertimbun kalau dimungkinkan, atau kemudian mengatur ulang kondisi muka tanah yang terjadi, juga membersihkan dari berbagai pepohonan yang tercerabut itu, atau membuka halangan-halangan yang mungkin berupa timbunan tanah lumpur di berbagai tempat. Kemungkinan juga melakukan tindakan pengamanan yang diperlukan seperti memindahkan rumah yang berada pada posisi rawan longsor misalnya.

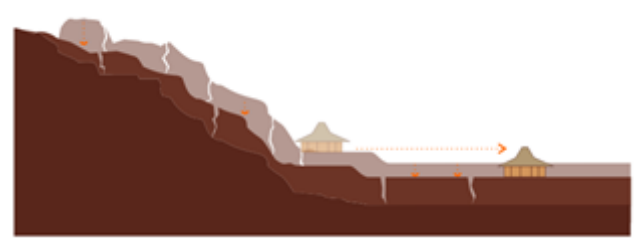

Gambar 6. Ilustrasi pasca bencana tanah longsor

Sumber: Dokumentasi tim penelitian, 2018 
Pencegahan Terhadap Bencana Tanah Longsor

Karena penyebab tanah longsor adalah intrusi air dan juga kecuraman kemiringan tanah maka untuk pencegahannya dilakukan dengan menghilangkan faktor pemicunya. Upayakan untuk menutup atau menimbun retakan di tanah yang potensial jadi pintu masuk aliran air hujan, juga mengurangi kemiringan muka tanah dengan membuat terasering sehingga air tidak meluncur terlalu cepat. Upaya lain yang bisa dilakukan adalah melakukan penanaman pohon untuk mengurangi erosi dan juga melakukan penataan saluran air sehingga air hujan menjadi lebih terarah dan tidak berbahaya menggerus tanah atau tebing yang terjal.

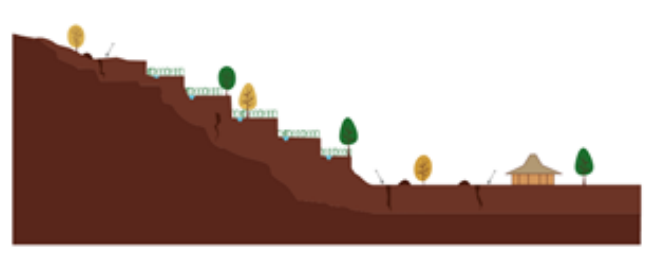

Gambar 7. Ilustrasi pencegahan terhadap tanah longsor

Sumber: Dokumentasi tim penelitian, 2018

\section{Kesimpulan dan Saran}

\section{Kesimpulan}

Tanda-tanda bencana merupakan sebuah sinyal yang penting yang mestinya harus diketahui oleh warga ketika menghadapi bencana. Tandatanda ini bukanlah disarikan dari teori atau wacana bencana, tetapi didapatkan dari pengalaman empiris masyarakat yang terkena bencana, yang tentunya hal itu merupakan akumulasi pengetahuan yang tersimpan selama ratusan atau bahkan ribuan tahun. Pada awalnya, pengetahuan itu tersimpan dalam tradisi lisan (yang dituturkan antar warga), yang ada kemungkinan terputus pada pergantian generasi.
Oleh sebab itulah, tanda-tanda awal bencana tersebut perlu dirangkum ke dalam sebuah pengetahuan tertulis yang nantinya bisa dibaca oleh banyak kalangan yang lebih luas. sehingga bisa bermanfaat untuk orang banyak ketika sewaktu-waktu akan terjadi bencana yang serupa.

\section{Saran}

Kesiapsiagaan dalam mengidentifikasi tanda-tanda bencana memang diperlukan dalam menghadapi bencana tanah longsor ini, tetapi yang lebih penting lagi adalah memberikan pemahaman kepada masyarakat bahwa bencana tanah longsor ini dapat dihindari jika mereka selalu menjaga harmoni dengan alam.

Dalam kaitannya dengan tanah longsor, harmoni terutama meliputi tiga unsur, yaitu: pohon/tanaman, tanah dan air yang harus dijaga keseimbangnnya. Lalu, tiga unsur itu juga menuntun kepada beberapa tindakan yang perlu dilakukan demi menjaga harmoni alamiah itu. Beberapa tindakan tersebut antara lain: menanam tanaman pencegah tanah longsor, membuat terasering, pengelolaan zonasi pertanian, kebun dan hutan, serta pengaturan saluran/drainase. Selain itu, juga perlu menanam pohon besar seperti gayam, aren atau asem, ditambah dengan konservasi sumber air sendang, sungai, atau mata air.

\section{Daftar Pustaka}

Moleong, Lexy J. (2007). Metode penelitian kualitatif. Bandung: PT. Remaja Rosdakarya.

Mekar, A. Kinasti. (2014). Pengaruh struktur geologi terhadap gerakan tanah di Dusun Windusari, Desa Metawana, Kecamatan Pagentan, Kabupaten 
Banjarnegara, Provinsi Jawa

Tengah. Jurnal Ilmiah MTG,

Vol. 7 No. 1 Januari 2014. URL:

//http.upnyk.ac.id/ diakses pada 15 November 2018.

\section{Ucapan Terima Kasih}

Terima kasih kepada Desa Kebonharjo, NGO Collaboration Center - Japan dan LPPM Universitas Kristen Duta Wacana yang mendukung tercapainya program kerja sama ini. 